\title{
Acompañamiento en educación inicial: voces de sus protagonistas en apertura al cambio
}

\section{Learning support in early childhood education: voices of its main actors in openness to change}

\section{Acompanhamento na educação inicial: vozes de seus protagonistas na abertura à mudança}

\author{
Ovidio Herrera-Rivera \\ Mónica Álvarez-Gallego \\ Universidad Católica Luis Amigó, Medellín, Colombia \\ Adriana Coronado-Mendoza (D) \\ Corporación por un Nuevo Santander, Medellín, Colombia \\ Natalia Guzmán-Atehortúa \\ Universidad Católica Luis Amigó, Medellín, Colombia
}

Open Access:

E-ISSN: $2665-2420$

ISSN: $0124-2121$

ARTÍCULO RESULTADO DE

INVESTIGACIÓN

Copyright @ 2020

By Educación y Humanismo

Editor:

Dhayana Fernández Matos

Universidad Simón Bolívar

En línea desde: 25-09-2020

I or caretakers aged between 2 and 5. Results: according to the teachers' perspectives, there is a significant absenteeism of the parents in the learning support process in early childhood education; the educational institution uses strategies such as calling a meeting by telephone or through notifications in children's notebooks; however their attendance to meetings is minimum; parents recognized limitations and they accept to get more involved in order to improve the support for their children. Discussion and Conclusions: the study found that early childhood education requires an articulated work between family, society and State taking into account the complexity of the subject matter; hence the need to integrate an analysis of the strategies, strengths and limitations which obstruct the process, in order to improve it under proper quality conditions.

Keywords: education, early childhood education, educational strategies, educational accountability, educational evaluation.

\section{Resumo}

Objetivo: analisar as estratégias de acompanhamentoatualmente utilizadas pelos pais, mães e / ou cuidadores e instituições na educaçãoinicial. Método: a pesquisa é qualitativa, na medida em que articula a construção e reconstrução dos significados vinculados àsexperiências dos participantes; Nesse sentido, foi utilizada a entrevista emprofundidade para obterinformações. Participaram do estudo 25 pessoas, como pais, mães e /ou cuidadoras e professorescomexperiência de acompanhamento na educação inicial de crianças entre 2 e 5 anos de idade. Resultados: de acordocom a perspectiva dos professores, háum acentuado absentismo dos pais no processo de acompanhamento na educação inicial; a instituição educacional utiliza estratégias como convocaçõestelefônicas, notificaçãoemcadernos para convocá-las; no entanto, suaparticipação é mínima; os paisreconhecemessalimitação, assumindocompromissocomsuamelhoria. Discussão e conclusão: o estudoconstatou que o na educação inicial requerumtrabalho articulado entre família, sociedade e Estado de acordocomsuacomplexidade; daí a necessidade de integrar umaanálise das estratégias, pontos fortes e limitações que a mediam, a fim de melhorá-la emcondições de qualidade.

Palavras-chave: educação, educação inicial, estratégias educacionais, responsabilidade e avaliação educacional.
Recibido: 01-05-2020

Aceptado: $30-07-2020$

\author{
Correspondencia: \\ Ovidio Herrera \\ ovidio.herrerari@amigo. \\ edu.co
}

DOI:

10.17081/eduhum. 22

39.3858 


\section{Introducción}

La educación de los hijos se concibe históricamente como responsabilidad inicial de los padres; compromiso vital que en ocasiones adolece de un acompañamiento sentido y significativo en algunos padres y madres contemporáneos, quienes han delegado dicha tarea a las instancias educativas e institucionales. De esta manera, la investigación realizada, nace como un cuestionamiento crítico de dos docentes investigadores, vinculados a las Facultades de Psicología y Educación de la Universidad Católica Luis Amigó, al interrogar el proceso de acompañamiento que actualmente realizan padres, madres y/o cuidadores en educación inicial (EI); algunos, ajenos y distantes en uno de los procesos más exigentes y complejos del ser humano como es la EI.

En este contexto, el compromiso de acompañamiento educativo no puede quedarse bajo la responsabilidad de los profesionales en educación, como tampoco en las instituciones que lideran este tipo de apoyo a las familias; como bien lo aclara el Congreso de la República a través de la Ley General de Educación (1994), en el artículo 70 "A la familia como núcleo fundamental de la sociedad y primer responsable de la educación de los hijos". (p.2).

En sintonía con estas ideas, la investigación busca generar comprensiones y visibilizar estrategias orientadas al bienestar de la comunidad educativa, representada por padres de familia, niños, niñas, maestros y personal administrativo.

En coherencia con estos intereses, la investigación se realizó en la Corporación por un Nuevo Santander, orientada al acompañamiento en EI, en convenio con el Programa Buen Comienzo adscrito a la Alcaldía de Medellín, del cual participan niños entre los dos y cinco años. La entidad se vinculó al proyecto de investigación en calidad de ente cofinanciador, aportando la experiencia institucional y parte del recurso humano y profesional para su cabal ejecución.

En concordancia con las premisas iniciales que llevaron al desarrollo del estudio, el informe de la Organización de las Naciones Unidas para la Educación, la Ciencia y la Cultura (UNESCO, 2004) señala que, desde un análisis crítico con respecto al acompañamiento de los padres en el proceso educativo, hay tres temas que se constituyen en objeto de reflexión en los últimos años, el primero, relacionado con los procesos de articulación institucional y familia en educación básica para facilitar los procesos de aprendizaje; el segundo, vinculado al reconocimiento de los padres como primeros agentes educadores y responsables de la socialización de sus hijos, y su influencia positiva en los procesos de aprendizaje y finalmente, un tercer tema que vincula los dos anteriores, en donde se centraliza la familia como espacio idóneo para facilitar la cobertura en los procesos de primera infancia. Considera a su vez este ente internacional 
que los centros educativos facultan un acompañamiento estratégico a las familias en el proceso complementario de educar, generar conocimiento y habilidades para la vida, además de facilitar el proceso de socialización temprana de los hijos; compromisos que gozan de alta complejidad en virtud de los atributos y exigencias que plantean las personas que participan de estos procesos, entre ellos niños, adolescentes, jóvenes y adultos. En este sentido, se requiere de maestros cualificados y con metodologías y estrategias adecuadas para el ejercicio de esta noble misión, así, "La escuela, la universidad y la educación, por su parte, deben adquirir un compromiso real con el acompañamiento a un ser humano capaz de reconocer y reconocerse en su historicidad, un ser humano capaz de ver y transformar su realidad" (Herrera, et. al, 2017, p.133).

En armonía a estos desafíos educativos, la Constitución Política de Colombia (1991), en el artículo 44, describe el proceso educativo como un derecho primordial del ser humano, en beneficio del desarrollo armónico e integral; de ahí la necesidad de ser cuidados y vigilados por las familias, por el componente social y el Estado. En este sentido, aclara el Estado, las instituciones estatales y privadas tendrán prioridad sobre la intervención y acompañamiento de la realidad infantil y adolescente en virtud de sus derechos, aspectos que implican, acorde al Programa Escuelas de Calidad (2010), un enfoque estratégico colaborativo y de liderazgo institucional compartido desde la asunción de responsabilidades acorde a cada realidad educativa.

En atención a estas perspectivas críticas en EI tendientes a su mejoramiento, la investigación plantea la pregunta ¿Cuáles son las estrategias de acompañamiento educativo que relacionan padres, madres y cuidadores/as e institución educativa en el fortalecimiento de la EI?

La investigación busca generar una reflexión sobre la EI, en tanto esta no solo es una responsabilidad de las instituciones educativas, los/as maestros/as y el Estado, por lo tanto, confiere aprestamiento especialmente de los padres, quienes se asumen como los primeros educadores de los hijos. De esta forma, el artículo convoca a padres y cuidadores a centralizar mayor atención en el acompañamiento de los hijos, en una de las dimensiones de mayor complejidad y exigencia en el proceso de crecimiento y desarrollo infantil como es la educación inicial, en alternancia con la corresponsabilidad. Es oportuno aclarar que la investigación no pretende agotar el tema de estudio, se espera que otros investigadores puedan tomar como referente los resultados obtenidos fortaleciendo de manera articulada la participación activa de los padres en el proceso educativo de los hijos.

\section{Fundamentos teóricos}

\section{Acercamiento normativo y teórico al concepto de educación.}

"Toda inversión en la educación básica debe evaluarse en función de dos parámetros: su utilidad para ampliar el acceso a la educación y su eficacia para mejorar el aprendizaje 
de todos sin excepción, niños, jóvenes y adultos" (UNESCO, 2005, p.5).En armonía a estos intereses, en el contexto de la realidad colombiana, la educación se concibe como prioridad en beneficio de la realidad económica y social, de ahí la necesidad de la gestión de recursos en aras de facilitar una educación accesible a todas las personas y con alta calidad. "El acceso a la educación ha sido una prioridad, con políticas ambiciosas que buscan incrementar el número de estudiantes matriculados en todos los niveles y llevar los servicios educativos a todos los rincones del país" (MEN, 2016, p.15). En sintonía, el Ministerio de Educación de Chile (1990), a través de la Ley Orgánica Constitucional de Enseñanza, en el artículo 2, considera que la educación, es un proceso permanente del ser humano a lo largo de la vida, que tiene por finalidad el desarrollo moral, intelectual, artístico, espiritual, y físico; mediados por la transmisión de valores, conocimientos y destrezas; aclara esta Ley, que corresponde primeramente a los padres la responsabilidad de educar a los hijos, por su parte el Estado, vigilará que este derecho se cumpla a plenitud. Robinson (2019), en complementariedad a estas normativas, señala: "Si tus hijos reciben una formación limitada, es posible que no descubran los talentos e intereses que podrían enriquecer su vida en el presente y servirles de inspiración para su futuro después de la escuela" (p.10).En Colombia, por su parte, el Congreso de la República de Colombia(1994), a través de la Ley General de Educación, describe la educación como un aspecto integral y necesario en las personas, premisa que comparte el Banco Mundial (2018) "La educación es un derecho humano, un importante motor del desarrollo y uno de los instrumentos más eficaces para reducir la pobreza y mejorar la salud, y lograr la igualdad de género, la paz y la estabilidad" (p.1). El MEN (2016) amplía estos intereses desde una perspectiva integral, indicando algunas acciones para mejorar el acompañamiento educativo, desde la primera infancia, entre ellas:

El mejoramiento de los resultados del aprendizaje, equidad de oportunidades educativas, capacidad para recopilar y usar datos para documentar las políticas, uso efectivo de la financiación para orientar las reformas, mayor participación de las múltiples partes interesadas en el diseño y la implementación de las políticas (p.3).

Históricamente el concepto de educación, ha sido motivo de interés para teóricos, investigadores e instituciones en el mundo, entre ellas la UNESCO, que amplíala comprensión de la educación referida a la calidad (Unesco, 1990, 2000a,b); aprendizajes adquiridos de manera integral, incluyendo el desarrollo cognitivo, creativo, físico, social y emocional (Unesco, 2005). La educación en atención a estas perspectivas, constituye un derecho a garantizar, que comienza desde la enseñanza infantil, la cual acompaña a la persona durante toda la vida, con objetivos que trascienden los procesos de cualificación profesional, mediada por procesos educativos necesarios para dar satisfacción a las expectativas de las personas en cualquier momento de su existencia (Herrera, et, al, 2017). Por lo tanto, la educación y el aprendizaje representan un ejercicio constante del ser humano, no vinculado a variables de edad, tiempo y lugar; implica aprender de acuerdo a necesidades comunes e intereses individuales; que sucede en cualquier lugar y 
momento de manera libre, flexible y constructiva (Delors, 1996).

\section{Acercamiento normativo y teórico al concepto de educación inicial}

De acuerdo al MEN (2017) "La educación inicial como proceso pedagógico intencionado, planeado y estructurado, propone oportunidades, situaciones y ambientes para promover el desarrollo de los niños y las niñas, de acuerdo con sus circunstancias, condiciones y posibilidades" (p. 26). En este contexto, cada sociedad, de acuerdo con sus prácticas socioculturales, presenta una comprensión y abordaje de la infancia, que describe la manera de nombrar y definirla, acorde con los niveles de atención, cuidado y oferta educativa. Para el MEN (2014), la EI representa un "Proceso pedagógico intencionado, planeado y estructurado, propone oportunidades, situaciones y ambientes para promover el desarrollo de los niños y las niñas, de acuerdo con sus circunstancias, condiciones y posibilidades" (p.43). En ese sentido, destaca la niñez con capacidades y destrezas con las cuales comprenden su mundo y el de los demás.

El Congreso de la República de Colombia(1994), mediante la Ley General de Educación, en aras de garantizar y promover el derecho a la educación en la niñez, concibe la educación preescolar como el primer escenario por excelencia para el crecimiento y desarrollo del niño y la niña, el cual incluye el conocimiento de su cuerpo, autonomía, la adquisición de identidad, motricidad, aprestamiento, motivación a la lectoescritura, solución de problemas, creatividad, aspectos lúdicos, aspectos de observación y exploración, dimensión espiritual, entre otros. Define a su vez, que "El nivel de educación preescolar comprende, como mínimo, un (1) grado obligatorio en los establecimientos educativos estatales para niños menores de seis (6) años de edad" (p.5).

En sintonía con lo anterior, Rodríguez (2018) señala que la primera infancia y con ella la EI, constituyen una de las etapas de mayor representatividad para el ser humano, que compromete aspectos físicos, cognitivos y sociales. Agrega el autor que, entre los 0 y 6 años, niños y niñas, moldean el desarrollo y el aprendizaje que serán soportes para su futuro, forjados en el seno de su familia, el contexto escolar, la sociedad y los procesos culturales.

El desarrollo integral de la niñez en EI, genera retos importantes en la manera de estructurar los planes curriculares, introduciendo apuestas de flexibilidad para captar la singularidad de la niñez de acuerdo con sus contextos de desarrollo, étnicos, sociales y culturales. El MEN (2017) considera que la EI y preescolar, están llamadas a promover espacios para el desarrollo armónico de la niñez, privilegiando en especial su aprendizaje; garantizando su protagonismo social y cultural, situándolos en el centro de la práctica pedagógica. Estos propósitos se definen a partir del reconocimiento de sus historias de vida y contextos de desarrollo de la realidad infantil, que a su vez constituye el derrotero para los maestros, de lo que se espera viva la niñez, como bien lo amplía el MEN (2017) mediante la "La Política de Estado para la Atención Integral a la Primera Infancia, de Cero 
a Siempre, Ley 1804 de 2016" (p.22), en la cual se dimensionan procesos normativos y técnicos centrados en el bienestar de la primera infancia, auspiciando el trabajo intersectorial.

A propósito, el MEN (2020) en Colombia reitera que es menester y responsabilidad de directivos, docentes, padres y madres facilitar un trabajo cooperativo, en pro de brindar a niños y niñas una educación de calidad, con ambientes adecuados para el desarrollo del aprendizaje, estimular su desarrollo y potenciar sus capacidades. Estas implicaciones como bien se observa, están referidas desde la normatividad nacional en primera infancia y con ella la EI, la cual representa igualmente compromisos y responsabilidades importantes para los padres: "llevarlos a la cama, y leerles un cuento y dormirlos, y que se despierten en medio de la noche porque tienen una pesadilla o se han hecho pis o porque sí, y calmarlos, y cambiarlos, y después dormirlos otra vez, ir a trabajar" (Rodríguez, 2019, p.14). Así, la cotidianidad de ser padres, en palabras del autor, representa un ciclo sin fin, pero a pesar de la complejidad, su tarea es "educarlos y enseñarles a ser buenos seres humanos" (Rodríguez, 2019, p.14).

\section{Estrategias de acompañamiento educativo en educación inicial}

Cobra representatividad en este análisis las palabras acompañar y estrategia en el proceso educativo del ser humano. Acompañar, significa "leer de manera consciente y contextualizada a los niños y las niñas en su acción, para transformar y diseñar el ambiente que habitan y usar diversas formas de estar para él o ella, ofreciéndoles aquello que necesitan" (MEN, 2017). Esas formas de estar o acompañar de los padres de familia, se recrean en las siguientes acciones: estar presentes desde la corporalidad, aspecto básico de la niñez en los procesos relacionales; implica a su vez acompañar desde el diálogo, es decir, facilitar puentes de comunicación mediados por la creatividad y el ingenio para leer la realidad infantil, posibilitando, además, una escucha activa, básica para participar de sus cuentos, de su creatividad, sueños y manifestaciones de alegrías, en fin un contexto de apertura para que la niñez desarrolle su oralidad, se exprese con el cuerpo, manifieste creatividad e ingenio.

En cuanto al concepto de estrategias, Contreras (2013) refiere que estas constituyen un aspecto importante en las decisiones institucionales, especialmente educativas, en donde los recursos deben gozar de un manejo óptimo a fin de asegurar los objetivos trazados; acorde con esta perspectiva, parte del éxito de la estrategia se concibe cuando se establecen los objetivos de la organización y se dimensionan los medios para alcanzarlos.

A tono con el contexto de bienestar infantil, maestros e instituciones educativas en EI precisan de acompañamientos pedagógicos, didácticos y humanos, en donde niños y niñas se sientan queridos, reconocidos y visibilizados; construyan identidad, creatividad y autonomía. Se precisa, además, de profesionales e instituciones que reconozcan los gustos de la niñez, identifiquen los procesos de crecimiento y desarrollo "A partir de las cuales pueden comprender el desarrollo infantil y desde allí potenciarlo" (MEN, 2017, p.34). Estos 
intereses, implican un relacionamiento comprometido y respetuoso entre quien cuida y es cuidado, asegurando ambientes, situaciones y contextos propicios para el bienestar infantil, entre ellos: el desarrollo de ambientes de aprendizaje, juego, creatividad, imaginación e innovación. Aclara el MEN (2020), que es obligatorio por parte de las instituciones que acogen niños en EI, brindar una acogida de calidad a niños y niñas, realizar actividades en el marco de permanencia con la institución, brindar el refrigerio, acoplar recesos y asegurar una despedida del niño con presencia del padre o cuidador. También este lineamiento es claro en exigir al cuerpo docente, ser delegados institucionales de las Redes de Aprendizaje, aspecto que les ayuda a intercambiar experiencias metodológicas, disipando inquietudes referidas a la experiencia en EI.

La normatividad nacional colombiana en educación en primera infancia, incluye a su vez algunas sugerencias que deben tener presente el personal docente y directivo, entre ellas: un clima de confianza y comunicación con la familia; información constante con los padres para conocer los hábitos del niño/a y las relaciones con el grupo familiar; desarrollar el afecto con todos los niños, dirigido al fomento de la confianza y la seguridad; instaurar rutinas sencillas desde el ingreso de los niños/as; instaurar hábitos de higiene y cortesía; reafirmar lo positivo y permitir los aspectos a mejorar como espacio para el cambio, entre otras. En armonía con estos intereses, el presente estudio, analiza las estrategias de acompañamiento que utilizan actualmente los padres, madres y/o cuidadores e instituciones de educación inicial.

\section{Método}

El enfoque de la investigación es de corte cualitativo, en tanto requiere de observación y proximidad del sujeto en su contexto, logrando un acercamiento a los significados de los fenómenos estudiados, privilegiando una metodología descriptiva, inductiva, holística y sensible, no intrusiva, comprensiva y humanista, en donde el sujeto es "digno de estudio" (Díaz, 2018, p.125). Para ello, se implementó la metodología de Análisis de Contenido (AC), la cual, según el autor, apunta a una perspectiva hermenéutica -interpretativa, que va más allá del contenido manifiesto y del mismo contexto, en donde se atribuyen algunas ventajas frente a su uso, entre ellas: procesos mediados por modelos comunicativos, con la inclusión de reglas y procedimientos que facilitan el proceso de análisis y resultados. Ruíz (2012) considera que esta metodología, incluye una amplia variedad de técnicas, que es preciso delimitarlas acorde con los intereses de cada investigación.

En correspondencia a lo expuesto, se hizo uso de la entrevista a profundidad, que en palabras de Galeano (2004), constituye una herramienta cercana a las experiencias de los participantes, que facilita su comprensión y análisis. En este sentido, la narrativa de los participantes es valiosa en la medida que vincula aspectos experienciales que, aunados al acontecer teórico, suscitan la adquisición de conocimiento en los procesos de acompañamiento educativo en EI.

Se elaboraron dos guiones de entrevista, uno para el equipo docente y otro para los 
padres, dado que ambos grupos introducen competencias y experiencias diferenciadas, pero en acoplamiento al proceso en EI. El primer guion, aplicado al cuerpo docente y directivo, incluyó preguntas asociadas a la experiencia educativa, entre ellas, imaginarios o significados de la educación: ¿Qué significa educar? ¿Qué importancia tienen los padres y cuidadores en el acompañamiento infantil? ¿La tarea de educar es exclusividad de los centros educativos? ¿Cuáles son las situaciones que fortalecen 0 debilitan el acompañamiento en EI? ¿Qué es Educación Inicial? ¿Cuáles son los atributos o cualidades de un docente en EI? ¿Qué actividades y estrategias realiza con los niños y niñas? ¿Cuáles son los compromisos y responsabilidades de la institución en el acompañamiento infantil? Entre otras preguntas que ayudaron a definir los objetivos propuestos.

El guion dos, corresponde a padres y cuidadores, el cual incluyó preguntas relacionadas con la experiencia y el acompañamiento en EI, entre ellas: ¿Qué significa educar? ¿Cuál es la importancia de los padres en el acompañamiento en EI? ¿Cree usted que la tarea educativa es solo de los centros educativos? ¿Qué situaciones fortalecen o limitan el acompañamiento en EI? ¿De qué manera se vincula usted con las actividades propuestas por la institución educativa? ¿De qué manera usted acompaña a su hijo (a) en EI? ¿Cuáles cree usted son los compromisos y responsabilidades de los padres y cuidadores en EI? ¿Cuáles son sus estrategias de acompañamiento en educación inicial, conoce usted las que propone la institución? ¿Cuál es la disposición de usted para acompañar a su hijo en las actividades propuestas por la institución?

Los guiones fueron revisados por personal experto en el tema, adscrito a la Facultad de Educación de la Universidad Católica Luís Amigó, validados por la Vicerrectoría de Investigaciones. Las entrevistas tuvieron una duración aproximada de una hora, fueron grabadas, previo consentimiento informado de los participantes, igualmente validado por Vicerrectoría de Investigaciones. El material recopilado producto de las entrevistas, pasó por el proceso de transcripción y codificación, análisis y escritura, contando con el apoyo del Software Atlas Ti V6. Para facilitar el proceso de análisis y resultados, se utilizaron matrices categoriales, en armonía con los objetivos del estudio.

Se realizaron 25 entrevistas individuales a profundidad, divididas en dos grupos para su estudio, uno de ellos conformado por siete maestras adscritas laboralmente a la Corporación por un Nuevo Santander y 18 padres/madres de familia y/o cuidadores/as, con hijos/as matriculados/as en dicha institución, quienes para su inclusión, debían de contar con un tiempo de permanencia superior a dos años en la institución, a fin de optimizar su experiencia; además de contar con un perfil de asistencia y compromiso con las actividades programadas por la entidad educativa. La institución facilitó la comunicación con los padres y las madres a través de contacto telefónico.

En cuanto a la caracterización de los/padres/las/madres de familia y/o cuidadores/as participantes, se puede señalar que, la mayoría, son madres que ejercen la jefatura femenina (monoparental); se observó la configuración de hogares nucleares, constituidos 
por matrimonio y uniones libres, con mayor prevalencia de estos últimos. Se observó también la constitución de algunas familias mixtas, las cuales aportan hijos de relaciones anteriores y los concebidos en la relación actual.

La edad de las madres se ubica entre los 18 y 40 años, la de los padres entre los 21 y 29 años, de los cuales solamente se contó con la participación de dos. Los padres aluden limitantes laborales para su participación, aspecto que fue evidenciado en un $90 \%$ de participación de las madres, el $10 \%$ restante, incluye a padres y cuidadores. La escolaridad de los participantes vincula el bachillerato, algunos aun sin finalizarlo; relacionan además estudios técnicos y universitarios en poca proporción. En relación con los estratos, las familias se ubican entre el uno y el tres, con mayor proporción en el dos y el tres. La ocupación de los padres es diversa: las madres, son amas de casa, otras, trabajan de forma independiente, especialmente en oficio doméstico, muy pocas en empleos institucionales mediados por un contrato laboral; los padres por su parte, presentan algún tipo de vinculación institucional o estatal. Los padres y/o cuidadores residen en la Comuna Seis de la ciudad de Medellín. Por último, es importante resaltar que el estudio contó con la participación de dos abuelas (cuidadoras), quienes asumen el acompañamiento de crianza de sus nietos, incluyendo el proceso educativo. En cuanto al perfil de las maestras que participaron en el estudio, estas debían contar con una formación mínima como técnicas en educación infantil, con experiencia acreditada superior a dos años en el acompañamiento en EI.

\section{Resultados}

Los resultados del estudio están en referencia a las categorías de análisis enunciadas anteriormente, para efectos de comprensión son retomadas: imaginarios en educación, Educación Inicial (EI), y estrategias de acompañamiento educativo en EI; se le dará mayor atención a esta última, en razón de sus resultados y aportes sobre el tema de estudio, categoría que a su vez incluye la subcategoría fortalezas y limitantes.

Imaginarios educación/educación inicial: de acuerdo con los resultados, se pudo evidenciar que padres, madres y maestras, consideran que el concepto de educación se encuentra asociado a guía, a orientación, a encaminar, enseñar, acompañar a las personas, considerando que la articulación y la corresponsabilidad de familia y escuela contribuyen significativamente en este proceso: "Educar para mí, significa guiar, encaminar; me refiero a diferentes contextos tantos en el hogar como en los diferentes entornos que está el niño" (Madre 3, 30 años). Por su parte la tarea de educar, se concibe como responsabilidad de las familias y el centro educativo: "La tarea de educar es de la familia y los centros educativos, porque si tiene educación aquí y no tiene educación en la casa entonces no está haciendo nada" (Madre 5, 30 años).Así, familias y maestras coinciden en que la educación empieza por casa, por lo tanto es responsabilidad de ambas 
instancias acompañar y apoyar los procesos institucionales.

Con respecto a la Educación Inicial, los padres no evidencian diferencias notorias entre el concepto de educación y educación inicial, consideran que esta última, corresponde a la etapa en la que se encuentran sus hijos (2 a 5 años), por lo tanto, asociada al acompañamiento educativo del centro infantil. Sin embargo, algunos padres frente al concepto, consideran que este espacio es vital, en tanto sus hijos pueden generar nuevos aprendizajes, relacionarse, jugar y recrearse, además de generar seguridad, puesto que están al cuidado de personal calificado y competente: "Para mí es muy bueno porque ella ha aprendido a relacionarse con otras personas, aprende a convivir con los niños. Sí, es como más como lo social, que aprende a socializar" (Madre 4, 27 años).

En sintonía con estas ideas, algunas maestras facilitan una descripción conceptual a la definición de EI: "Es ofrecer a los niños todas esas habilidades, o sea, vamos a fortalecer motricidad, vamos a tener un auto-reconocimiento, la identidad, o sea es como fortalecer en los niños y darles como esas bases, entonces sí es muy, muy importante" (Docente, 2, 27 años). Por su parte una madre entiende el concepto de EI a tono con el nombre: "Es como la primera educación que uno recibe, porque dice educación inicial" (Madre 11, 28 años). Otra madre amplía el concepto de EI, el cual relaciona al desarrollo y crecimiento del niño-a, en afinidad con la motricidad, la adquisición de buenos modales, aprendidos inicialmente en casa y ampliados en la institución educativa: "Yo siento que mi niña se beneficia cuando le enseñamos buena educación, cuando dice "por favor", "gracias", "con mucho gusto" (Madre 11, 28 años).

Los aspectos relacionales igualmente se hacen evidentes en los testimonios de los padres, generando conciencia sobre la importancia de que sus hijos puedan establecer contacto con sus iguales, vinculando aspectos de socialización, juego y creatividad, además de fortalecer rutinas y hábitos, valores, adquirir modales; a su vez visto el contexto educativo como un espacio para compartir y desarrollar competencias y habilidades sociales que contribuyen con el desarrollo infantil.

Estrategias de acompañamiento en EI: en referencia a los resultados, estas se dividen en dos grupos para su análisis y comprensión: las empleadas por la institución y las implementadas por los padres en el proceso educativo. En cuanto a las estrategias institucionales en el componente pedagógico, se observa al niño como sujeto activo de acompañamiento: "Como vigilar, estar atentos a cada necesidad de los niños y las niñas, porque ellos constantemente tienen necesidad de algo, entonces más que todo estar como al pendiente de cada uno de ellos y mirar la necesidad de cada uno" (Docente 6, 30 años).

Articulado a las necesidades infantiles, la institución plantea un currículo flexible que, lejos de generar adoctrinamientos, permita que el niño o niña explore, se recree, conozca, se relacione e interactúe consigo mismo, con los demás, como también con su contexto: 
"Nosotras no nos guiamos por ninguno currículo, si no que como surge de las voces de los niños, todo surge de un momento a otro". (Docente 7, 49 años). Los padres por su parte, de acuerdo con sus experiencias, refieren la necesidad de acompañar a sus hijos en el proceso educativo: "Los niños necesitan, y más un niño en crecimiento, necesita de la compañía de los padres para todo, para el aprendizaje, para el comportamiento y yo creo que nosotros como padres queremos que los hijos sean lo mejor..." (Madre 2, 29 años).

En línea con los procesos pedagógicos, se incluye el componente afectivo, eje transversal del mismo, visto por el grupo de maestras como un factor básico en EI, en donde el niño/a precisa de demostraciones de cariño y afecto que, articuladas con el acto pedagógico, ayudan a fortalecer el acto formativo: "El colegio me gusta mucho porque las profesoras tienen el don para estar con los niños, tienen paciencia, amor, les enseñan"(Madre 7, 25 años). Por su parte el juego, como estrategia educativa, facilita que el niño o niña aprenda de sí mismo y de los otros, aspecto que es compartido por padres y maestras: "Aprenden también muchas cosas acá, les enseñan juegos, a cantar, pero para mí ha sido más importante como la socialización" (Madre 10, 27 años).

Otra estrategia implementada por la institución educativa afín a los objetivos pedagógicos, está referida a la convocatoria de los padres a las diferentes actividades formativas. Los medios son diversos, incluyendo el cuaderno viajero, las redes sociales, contacto telefónico, carteleras: "Los niños tienen un cuaderno viajero y ahí le mandan a uno las notas" (Madre 10, 27 años). En relación con este tema, las maestras consideran que la baja participación de los padres en las actividades institucionales, se constituye en limitante en EI, entre ellas: encuentros lúdicos, recreativos y formativos, en concordancia con los objetivos formativos, los cuales ayudan a fortalecer el compromiso y responsabilidad de los padres, en donde el diálogo, la cooperación, se convierten en los principales aliados para favorecer el trabajo realizado con niños/as:"Sí traerlos, como que mostrarles... ellos traen a los niños y a las niñas y no ven qué pasa, simplemente los dejan ahí, sería rico, coger un grupo de padres que van a estar todo el día en el jardín". (Docente 6, 30 años).A este acompañamiento, se agregan grandes dosis de flexibilidad $y$ paciencia en el acompañamiento educativo en el grupo de maestras, que constituyen, según los padres, una manera inteligente de facilitar dicho proceso: "tratamos de enseñarle los números con juegos, o sea más como, que no sea algo obligatorio" (Madre 13, 36 años).

Fortalezas y limitantes en EI: la confianza se observa como una gran fortaleza institucional en beneficio de los padres, en virtud de sentirse apoyados con profesionales capacitados, que acogen a sus hijos, les brindan conocimientos y afecto, además de implementar estrategias educativas que favorecen el desarrollo de la creatividad, el juego, la autonomía y el aprendizaje en sus hijos: "Súper cómoda, muy contenta por lo que te digo, yo he visto mucho avance en la niña. Yo hasta el momento estoy conforme con todo, con el trato de las profesoras, le informan a uno siempre cómo van los niños". (Madre 7, 25 años). 
Acorde con la realidad de los padres que laboran y que su tiempo se ve menguado para acompañar a sus hijos, se incluye el acompañamiento educativo por parte de cuidadores, usualmente la familia extensa, en la que se involucran abuelas, abuelos, tíos, primos, entre otros. La participación de abuelos/as es representativa, los/as cuales se sienten a gusto con dicho acompañamiento, sin dejar de admitir que son otros tiempos, en donde su edad y el momento actual de la niñez plantean exigencias de alta complejidad que se salen de control; igualmente son conscientes de estas limitantes, pero hacen claridad que el apoyo lo dan como una manera de colaborarles a sus hijas e hijos, dado que sus ocupaciones laborales dificultan el acompañamiento de crianza: "Mi hija no pueda venir a participar, entonces ya me toca a mí... apoyo en las actividades que dice la profe (...). Uno debe de seguir esa enseñanza con ellos en la casa, por ejemplo, hacer tareas, estudiar con ellos..." (Madre/abuela 8, 65 años). En este acompañamiento educativo, también se hace representativo el apoyo de vecinos y amigos, los cuales consideran que hacen el apoyo de manera desinteresada, pero en lo factible están de acuerdo con que los padres son los directos responsables de este acompañamiento. Las maestras, por su parte, relacionan dificultades con el apoyo de cuidadores/as al no comunicar a las madres y las padres situaciones de seguimiento de sus hijos en el preescolar: "Cuando son los vecinos, yo pienso que es más por hacerle el favor a la familia, porque la mamá no está" (Docente 7, 28 años).

Con respecto a las limitantes en EI, se identifican algunos aspectos críticos que, de acuerdo con el personal docente, ameritan ser reflexionados, entre ellos, un marcado ausentismo en algunos padres, quienes presentan prácticas delegatorias en crianza, aspecto que, a su modo de ver, están fuera de contexto, dado que sus competencias profesionales obedecen a un componente educativo no parental. Las docentes aclaran que su rol es complementario al proceso educativo iniciado en el hogar, desde el cual se logran los objetivos de formación en niños y niñas.

El siguiente testimonio genera reflexión sobre la participación de las madres y los padres en el proceso educativo, introduciendo la necesidad de cooperar activamente: "la educación inicial no es solo de la profe, del jardín, es una articulación. Yo digo que no solo familia sino de todos los entes [formativos]" (Docente 6, 30 años). No obstante, la delegación parental se hace recurrente en algunos padres, asociada al cuidado y responsabilidad de sus hijos por parte de terceros, amigos o vecinos o familia de origen. Este tipo de prácticas es considerado por algunas maestras como nociva, al no aportar en el desarrollo, crecimiento y acompañamiento educativo de sus hijos, situación que precisa la presencia y participación activa de los padres. Refiere el grupo de maestras que, el ausentismo de los padres, no opera solamente en la institución, se hace evidente también en el hogar, generando afectaciones educativas, relacionales, conductuales y emocionales: "Cuando uno no recibe un buen acompañamiento desde el hogar ¿qué se observa? Niños aislados, niños que no quieren interactuar, niños que son muy temerosos" (Docente 1, 32 años). 
Otra limitante en el acompañamiento en EI está representada en el déficit de tiempo para compartir en familia, en el cual los padres expresan especialmente razones laborales; colmados/as de jornadas largas que impiden participar en tiempos de recreación, lúdica, diálogo, incluso de cercanía afectiva, en especial con sus hijos. En menor proporción incluyen limitantes sociales, enfermedad y escolaridad: "Todo es trabajo, trabajo y trabajo y se olvidan de los niños" (Docente 1, 32 años). Las limitantes de tiempo, se convierten en un aspecto de preocupación en padres y maestras que motiva a su mejoramiento: "Nosotros estamos muy pendientes de hablarle, de siempre recordarle las cosas buenas, de dedicarle más tiempo y ser muy cuidadosos con ella" (Madre 1, 34 años).

Las maestras concluyen que la poca disponibilidad de tiempo y las excesivas demandas laborales en los padres, dificultan una participación activa en los procesos pedagógicos en condiciones de calidad y compromiso. A manera de síntesis, la tabla 1 recopila de manera general, algunas estrategias, fortalezas y limitaciones que presentan alta relevancia en EI a partir de los resultados del estudio, en atención al nivel de recurrencia desde la perspectiva de padres/madres, cuidadores/as y maestras de la institución educativa.

Tabla1.

Estrategias, fortalezas y limitantes: maestra, padres/madres y cuidadores/as

\begin{tabular}{|c|c|c|}
\hline Estrategias & Fortalezas & Limitantes \\
\hline $\begin{array}{l}\text { "Con Buen Comienzo trabajamos proyección } \\
\text { desde la experiencia que son esos proyectos } \\
\text { de exploración que surgen a través de las } \\
\text { voces de los niños y las niñas y los intereses" } \\
\text { (Docente) }\end{array}$ & $\begin{array}{l}\text { "Las ganas, el cariño que le tenga a su } \\
\text { profesión (...), alegres, que bailen, salten y } \\
\text { jueguen". (Docente) }\end{array}$ & $\begin{array}{c}\text { "Que los niños lleven un cuaderno que le } \\
\text { pongan tareítas, que hagan un planita, } \\
\text { bueno, eso son cosas que uno piensa" } \\
\text { (Madre) }\end{array}$ \\
\hline $\begin{array}{c}\text { "Les brindamos unos materiales y eso nos } \\
\text { satisface mucho, porque nosotros trabajamos } \\
\text { más que todo con material didáctico " } \\
\text { (Docente) }\end{array}$ & $\begin{array}{l}\text { "Buen Comienzo pues me pareció muy } \\
\text { bueno. ¿Por qué? Porque les ofrecían muchos } \\
\text { beneficios como el cuidado todas esas horas, } \\
\text { porque uno puede ir a trabajar, se los cuidan } \\
\text { a uno gratis, le dan su alimentación muy } \\
\text { buena" (Madre) }\end{array}$ & $\begin{array}{c}\text { "Poder involucrar un poco más a los padres } \\
\text { en las actividades que hagan dentro del } \\
\text { colegio" (Docente). }\end{array}$ \\
\hline $\begin{array}{l}\text { "Todo parte de las voces de los niños, todas } \\
\text { las ambientaciones, o sea las cosas que se } \\
\text { hacen para colocar debe partir de los niños, } \\
\text { todo, no debe estar intervenido por un } \\
\text { adulto, debe de ser hecho por los niños" } \\
\text { (Docente) }\end{array}$ & $\begin{array}{l}\text { "Me da la ventaja de verla cada día desarrollar } \\
\text { sus habilidades, de tener la seguridad que mi } \\
\text { niña está en un buen crecimiento" (Madre) }\end{array}$ & $\begin{array}{l}\text { "Si es el caso que muchos niños viven } \\
\text { con abuelitos, los abuelitos no los llevan a } \\
\text { los Centros Educativos" (Docente). }\end{array}$ \\
\hline $\begin{array}{l}\text { "La responsabilidad de las profes siempre } \\
\text { estar ahí con los niños educándolos, } \\
\text { observando si comen, si no comen" (Docente) }\end{array}$ & $\begin{array}{l}\text { "Somos una familia muy unida. Sí, como que } \\
\text { prima el respeto, la niña no está en un } \\
\text { entorno como violento o algo así" (Madre). }\end{array}$ & $\begin{array}{l}\text { "Mi esposo llega tarde de la noche por su } \\
\text { horario de trabajo, por lo regular no tiene } \\
\text { tiempo para compartir con su hija" (Madre) }\end{array}$ \\
\hline $\begin{array}{l}\text { "Entonces era como muy difícil ya uno como } \\
\text { agente educativo como ya ponerse ahí a } \\
\text { resolver todo, entonces es como la } \\
\text { participación y la buena comunicación que ya } \\
\text { tenemos como con los papás para poder } \\
\text { hacer un buen trabajo" (Docente). }\end{array}$ & $\begin{array}{l}\text { "Los padres están fortalecidos en la } \\
\text { institución a asistir a las reuniones, a los } \\
\text { encuentros de padres de familia". (Madre) }\end{array}$ & $\begin{array}{c}\text { "Muchas veces no se cuenta pues como con } \\
\text { la suficiente participación de la } \\
\text { familia"(Docente). }\end{array}$ \\
\hline $\begin{array}{l}\text { "Un día con los niños es un día de bailar, de } \\
\text { crear, de explorar, de escucharlos; o sea, es un } \\
\text { momento donde ellos vienen a disfrutar pero } \\
\text { también vienen a aprender" (docente). }\end{array}$ & $\begin{array}{c}\text { "Salen muy aprendidos, cuando ya... } \\
\text { disque los grados pues de que ya salen } p^{\prime} \\
\text { transición ellos salen muy aprendidos, ellos } \\
\text { llevan un cuaderno, saben las vocales, ya } \\
\text { saben mucha cosita" (Madre) }\end{array}$ & $\begin{array}{l}\text { "Entonces la profe sola con tantos niños, } \\
\text { mientras que en la casa uno tiene la } \\
\text { oportunidad de dedicarse solamente al hijo } \\
\text { de uno..." (Madre). }\end{array}$ \\
\hline
\end{tabular}

Fuente: Resultados del estudio 


\section{Discusión}

\section{Imaginarios educación/educación inicial: padres, madres y cuidadores/as}

Mora y Maestre (2012) en el contexto de la familia, sustentan que "En su tarea socializadora, la familia cumple con la trascendente función social de preservar y transmitir los valores y tradiciones del pueblo, sirviendo de enlace a las generaciones". (p. 15). Al respecto, y en correspondencia con la función educativa de los padres, consideran que la educación inicial es una etapa necesaria, comprendida entre los 2 a 4 años, en donde el acompañamiento familiar y escolar, se constituyen en eje articulador. Compartiendo algunas perspectivas, padres, madres y maestras, coinciden en ver la EI como un ámbito humano, asociado a la guía, la orientación, a encaminar, enseñar y acompañar a las personas para su desarrollo y crecimiento, haciendo énfasis en la articulación familia y escuela, en el marco de una corresponsabilidad en condiciones de calidad, eficiencia y compromiso.

Reveco (2006, citada por la Unesco, 2004), señala que la educación representa una responsabilidad directa de los padres, siendo la familia el lugar por excelencia para el aprendizaje, articulada a ella, otros contextos como el barrio y la ciudad. En correspondencia, los centros educativos, a través de sus docentes, relacionan competencias especializadas frente al proceso educativo iniciado por las familias, logrando condiciones de calidad y bienestar para la población infantil. En congruencia, el siguiente testimonio considera que la EI, se constituye en un espacio de socialización y de adquisición de habilidades, buenos modales y valores, factores que a su modo de ver trascienden la adquisición de conocimientos: "eso hace ver que estamos formando a alguien que en el futuro va a reflejar la buena educación que le dimos en la casa o ya sea en la guardería, en el colegio". (Madre 11, 28 años).

Por lo tanto, la EI representa un espacio dirigido a la visibilización de capacidades y habilidades para la existencia. Mantilla (2003, citado por Preciado 2014), refiere que este tipo de habilidades vinculan competencias psicosociales e interpersonales, que favorecen la toma de decisiones, la comunicación efectiva y estratégica y el desarrollo de capacidades para afrontar y resolver eventos cotidianos, factores que contribuyen a una vida saludable y productiva. En afinidad, y acorde a la perspectiva de padres y cuidadores, la EI está asociada con la edad en la que se encuentran sus hijos, comprendida entre los dos y cuatro años; etapa de desarrollo, que requiere dada su complejidad, del acompañamiento educativo institucional, en especial de los centros infantiles: "Es como esos primeros pasos que el niño da, como ese acompañamiento en donde se le muestra al niño el mundo, el mundo que lo rodea". (Docente 6, 30 años), el cual precisa de responsabilidad compartida entre padres de familia e instituciones educativas.

\section{Imaginarios educación/educación inicial: maestras e institución educativa} En referencia a estos imaginarios, Rodríguez (2018) refiere que las creencias personales, familiares, sociales, culturales y políticas, influyen notoriamente en los procesos de transformación y bienestar de niños y niñas en EI, en este sentido, es propio generar un 
accionar que vigile, regule y garantice tan exigente propósito, en especial en el personal que acompaña cotidianamente dicha labor. En concordancia con el autor, el grupo de maestras indican que la EI requiere atención especial, en tanto es un espacio vital que provee conocimientos y valores, que ayudan al ser humano a su desarrollo cognitivo, la adquisición de habilidades y destrezas para la vida. De esta forma, se confiere especial atención y valor en la EI, desde la cual se ayuda a potenciar y enriquecer el aprendizaje infantil; proceso que dada su complejidad, incluye la participación decidida, comprensiva y colaborativa de padres y cuidadores.: "Educa la sociedad, educa la familia, educa la escuela" (Docente 1, 32 años). Es preciso advertir en este punto de análisis, que las familias en el momento que matriculan a sus hijos a una institución educativa, generan acompañamiento, compromiso y responsabilidad en este proceso, como bien lo resalta la Unesco (2004), al destacar la participación activa de los padres en el aprendizaje de los hijos, insistiendo para ello, en la cooperación necesaria y articulada entre las familias y la institución educativa.

Existe acorde a estas ideas, un reconocimiento por parte de las familias y el equipo de maestras que la educación empieza por casa, aspecto que se hace reiterativo en las percepciones de algunos padres; sin embargo, se evidencia un marcado ausentismo de éstos en el proceso educativo de los hijos, aspecto que dista del siguiente testimonio, en donde se hace evidente la necesidad de instaurar un acompañamiento real y sentido de los padres "La educación parte es más desde el hogar, desde ahí lo forman a uno, con valores, principios, el ejemplo, usted decía ahora del ejemplo, es muy importante de qué ejemplo le estoy dando yo a mi hijo" (Madre 11, 28 años). En esta línea, las responsabilidades y derechos propios del proceso educativo son validados en la Política Pública y Social de Primera Infancia 2007, al describir que las capacidades, estructuras y dotación infantil, obedecen principalmente a la interacción de sus experiencias con la realidad adulta y el contexto. En lo respectivo al hogar, estos procesos configuran la crianza, base fundante del proceso educativo, que se adelanta al entorno educativo institucional posibilitando en los hijos e hijas, el desarrollo de la identidad, la autonomía y legitimización del otro.

Fullan y Stiegelbauer (2003 citados por Pizarro, Santana y Vial, 2013), indican "que cuanto más esté el padre cerca de la educación del niño, tanto mayor será el impacto en la evolución y logros educativos del niño". (p.276), de allí la necesidad de trabajar articuladamente para comprender las necesidades propias de la niñez, puestas en reflexión - acción desde los estamentos educativos, gubernamentales y sociales. Por su parte, trabajar con niños y niñas, incluye, desde el rol del docente, la habilidad para generar acciones de bienestar en la población infantil (Glazman, 2005, citado por Preciado 2014): "En la EI, ¿qué es lo que hace?, o sea es como ofrecer a los niños todas esas habilidades, o sea es vamos a fortalecer motricidad, vamos a tener un autoreconocimiento, la identidad". (Docente, 27 años).

En sintonía con estas perspectivas, Rodríguez (2018) refiere que "En [la] interacción 
entre maestra y niño/niña, [se] adquiere un papel determinante en el que se reconoce a la primera infancia diversa en la que es necesario visibilizar al niño y la niña como seres únicos con habilidades, capacidades y necesidades diferentes" (p. 5). En este contexto, las maestras definen la EI como la etapa comprendida entre los 2 a 4 años, representado en el ingreso del niño(a) a un centro infantil, en donde entre los 3 y 4 años de edad, fortalecen modales, adquieren rutinas, hábitos y valores; representando a su vez, un espacio para propiciar las interacciones entre sus iguales, con los cuales pueden compartir, desarrollar competencias y habilidades sociales, motricidad fina y gruesa, que contribuyen a su desarrollo integral, aspecto que se integra sustancialmente a las perspectivas expuestas por Rodríguez (2018).

\section{Estrategias de acompañamiento en educación inicial: maestras e institución educativa}

Maldonado, Benavides y Buenaño (2017), consideran que la estrategia tiene un propósito, es decir, un medio para establecer los propósitos institucionales, en términos de planes, programas, proyectos y consecución de recursos; implica, además, una visión global, coherente y unificado de la organización como un todo para asegurar los objetivos propuestos; vincula a su vez el entorno, al generar respuesta a las fuerzas y debilidades internas, a las oportunidades y amenazas presentes. Ferreiro (2006, citado por Gutiérrez, 2018) en afinidad a estas tesis, considera que "el concepto de estrategia ha sido transferido al ámbito de la educación en el marco de las propuestas de enseñar a pensary de aprender a aprender"(p.85). Entre las estrategias institucionales desarrolladas por los y las docentes, está la vinculación de los padres en el proceso educativo, a través de temas de interés en primera infancia, como la afectividad, la comunicación familiar y charlas sobre nutrición; se incluyen en este grupo de estrategias, la invitación constante al desarrollo de actividades lúdico - recreativas, y académicas, en pro de instruir a las familias en el tema de infancia, además de favorecer su inserción en los procesos institucionales. Sales, Moliner, Amiama y Lozano (2018) indican que las actividades lúdicas y enfocadas en las familias, como las celebraciones y momentos de ocio son las que tienen mayor resonancia en el entorno. A modo de aclaración, frente a la articulación de estrategias en el contexto educativo, Pitluk (2016) considera que la estrategia no implica solamente relacionar acciones para articular niños, ámbitos y experiencias pedagógicas requiere, además, permanencia y revisión constante de estos procesos en beneficio de los estudiantes.

A propósito de estrategias educativas, Rodríguez (2018) resalta que los maestros en EI, estructuran un rol de relevancia y responsabilidad en la formación infantil, al fortalecer herramientas, capacidades y habilidades en niños-as. Así, la diada maestra-niño/a, integran estrategias para comprender las necesidades y demandas de la población infantil, incluyendo sus vivencias, situaciones y experiencias; que permiten de construir imaginarios sociales de padres, madres, cuidadores y los mismos docentes, en beneficio de la primera infancia. "En ese sentido, la educación inicial como proceso pedagógico 
intencionado, planeado y estructurado, propone oportunidades, situaciones y ambientes para promover el desarrollo de los niños y las niñas, de acuerdo con sus circunstancias, condiciones y posibilidades" (MEN, 2017, p.26). La institución educativa, a su vez, hace uso de estrategias pedagógicas y didácticas, mediante la exploración y el juego intencionado para promover experiencias significativas, buscando que niños y niñas disfruten las jornadas y faciliten su aprendizaje, partiendo de sus inquietudes e intereses: "Una variedad de temas que uno cada mes les va haciendo, va como proyectando, pero que surgen de las voces y de las necesidades de ellos" (Docente 5, 28 años).

Lo anterior, va de la mano con lo planteado por la Presidencia de la República (2013), en donde el juego, el arte y la exploración, constituyen actividades propias de la primera infancia, que permiten representar la realidad infantil, articulado al contexto, sus pares, y el mundo de los adultos. En correspondencia con estos lineamientos, la institución educativa establece una rutina diaria que consta de diferentes momentos como la alimentación, el juego, el aprendizaje y el descanso. De acuerdo al MEN (2017), los niños igualmente precisan de interacciones recurrentes en su cotidianidad, especialmente con sus iguales, y con el contexto, conjugando aprendizajes y sentimientos que favorecen su crecimiento, desarrollo y sentimientos desde el ser, hacer y pensar. Sin embargo, llama la atención que la mayoría de los padres entrevistados no tienen claridad de estos acompañamientos curriculares y pedagógicos, lo que valida la importancia de instruir a los padres de familia en este tipo de estrategias conducentes a una mayor participación en las actividades programadas. (Pizarro, Santana y Vial, 2013).

En sintonía con estos autores, la institución educativa con la que se trabajó en esta investigación, considera que su propósito es guiar a los niños/as y a las familias mediante una atención integral, es decir, brindar a la niñez protección, alimentación, cuidado, recreación y salud, y a las familias un acompañamiento oportuno y profesional, en el aspectos pedagógico, emocional y psicológico. En este punto, los padres y madres de familia entrevistados aseguran recibir satisfactoriamente estos servicios, mostrando conformidad con el acompañamiento institucional: "Para mí todo está bien, es que el apoyo que le han dado al niño ha sido mucho porque se le ha visto el avance" (Madre 3, 30 años).

De esta forma, los padres de familia destacan el acompañamiento del equipo de maestras, en las cuales identifican los siguientes atributos: amor por la vocación, una comunicación constante con la familia al brindar confianza y respaldo tanto a los niños/as como a las familias; enseñan desde el buen ejemplo y motivan al aprendizaje. Con respecto a estos atributos, Rivas y Ugarte (2014) mencionan que la reflexión que realicen los maestros sobre su accionar en el aula, se constituye en un componente esencial al momento de detectar vacíos que operan en la relación con los padres, por lo cual, el docente representa una "pieza clave y colaboradora directa en el proceso educativo, capaz de asumir el control, tomar la iniciativa y responsabilizarse del proceso educativo" ( $p$. 162). 


\section{Estrategias de acompañamiento en educación inicial: padres, madres y cuidadores/as}

En este nivel de análisis, cabe mencionar la visión de estrategias educativas familiares presentada por Gubbins \& Ibarra (2016), quienes proponen una articulación de cuatro dimensiones: el soporte económico y los aspectos culturales de las familias; los sueños de los padres depositados en sus hijos y las prácticas de crianza. Referente a estas dimensiones, se encuentra que las familias, emplean en mayor medida premios y castigos de acuerdo al comportamiento de sus hijos: "Como él se portó mal ese día yo le dejé en la habitación de él y le dije: como se portó tan mal, ahí lo voy a dejar, y no va a ver televisión.,". (Madre 18, 22 años).

De igual forma, los padres de familia disponen de otros mecanismos para incentivar a los niños a que mantengan un comportamiento esperado, especialmente en el contexto educativo: "Los viernes, por lo general, ella sabe que si en la semana se fue portando relativamente bien, la llevamos a la piscina de juguetes, ese es su premio, y ella ya con eso se entretiene mucho" (Padre 10, 30 años).

También toma un papel importante la motivación e interés de los padres hacia los hijos, resaltando la importancia del tiempo de calidad, al igual que el refuerzo en el hogar de los aprendizajes adquiridos en la institución educativa "A veces no es el tiempo, sino la calidad del tiempo, la calidad del tiempo que le damos a los hijos" (Madre 11, 28 años). Además, es importante destacar la atención que brindan algunos padres a sus hijos en el hogar "yo casi siempre cuando ella llega del jardín ya me dedico es a ella, esa es la ventaja pues de uno trabajar en la casa" (Madre 15, 29 años).

Se observa, igualmente, un acompañamiento educativo en los padres de familia basado en la realización de tareas escolares, mediado por el compromiso, la responsabilidad, la cooperación y el diálogo:"yo busco formas de hablarle a veces jugando, a veces pues le hablo fuerte, pero la mayoría de las ocasiones me funciona mucho cuando hablo con él" (Madre 2, 29 años). Sobre este tema, Herrera, Bedoya y Alviar (2019) confirman estas ideas, encontrando que algunas familias en el proceso de crianza, dedican tiempo libre para compartir, jugar con los hijos, ver televisión, disfrutar una comida y dialogar, aspecto que dista de los resultados del estudio de Fuentes, Restrepo, Rodríguez y Vásquez (citados por Lastre, López y Alcázar, 2018), quienes encontraron que las familias presentan escaso tiempo para acompañar a sus hijos en las tareas educativas, limitadas por aspectos laborales o simplemente existe poca motivación para hacerlo. Aun así, los padres entrevistados, en reconocimiento de estas limitantes, buscan mejorar su disposición, compromiso y flexibilidad en el acompañamiento educativo de sus hijos: "no hacérselo como imponiéndoselo, porque obviamente ella le va coger pereza, entonces trato de hacérselo como divertido, para que a ella le guste" (Madre 4, 27 años).

Otro elemento que se destacó en este estudio fue la participación predominante de la 
madre en el acompañamiento educativo de los hijos, basado en transmitir, enseñar, educar y mediar, para posibilitar momentos de unión y de compartir en familia, siendo además responsable de las labores del hogar, en donde la familia y en especial las madres son las encargadas de la enseñanza de valores y principios familiares, en algunos momentos aparece la figura de los/as abuelos/as, como partícipes en el proceso de crianza y acompañamiento educativo de los/as nietos/as, aspecto que se constituye en un elemento a tener presente en investigaciones futuras. Estos resultados concuerdan con el estudio de Payá y Tormo (2016) sobre una mayor participación de las madres en el acompañamiento de los hijos, mientras que los hombres tienen una mayor permanencia en sus empleos, las mujeres, por el contrario, en su mayoría son amas de casa, por lo tanto con mayor dedicación al cuidado infantil: "Yo siento que yo estoy bien, o sea, a mí me va muy bien, tal vez la calidad de tiempo que le falta a mi esposo pasar un poco más de tiempo con ella..." (Madre 11, 28 años).

Dentro del grupo de estrategias de los padres en el acompañamiento educativo se dimensiona la importancia del diálogo y el involucramiento del núcleo familiar, incluyendo las redes de apoyo familiar: mamá, papá, hijos, hermanos, abuelas y tías y, en un plano externo, la participación de vecinos y amigos, quienes habilitan acompañamientos estratégicos, en atención a las limitantes familiares, laborales, académicas, de enfermedad, entre otras, relacionadas por padres y madres.

De acuerdo con Álvarez (2016), el acompañamiento infantil se construye en la intersubjetividad de adultos y niños/as, mediada por interacciones y cuidados que incluyen aspectos de nutrición, sanitarios, emocionales, relacionales, de inserción social, de la cual participan diversos actores, estilos, pautas, prácticas y roles; el abuelazgo, es decir el acompañamiento en crianza delegado a los abuelos, representa un buen ejemplo acorde a los resultados: "Hay niños que los acompaña la abuela porque el papá y la mamá trabajan. Hay otros que hace el ambiente la mamá y otros que puede ser solo el papá, hay unos niños que la tía es la que siempre está acompañando ese proceso" (Docente 1, 32 años). En este nivel de análisis, la corresponsabilidad educativa se hace recurrente en el discurso de padres, madres y maestras, cobrando importancia el trabajo cooperativo entre la familia e institución, facilitando, según ellos, una relación colaborativa y de acompañamiento mutuo en los procesos y actividades promovidos institucionalmente de manera coherente y articulada.

A modo aclaratorio, es oportuno advertir que estos resultados no son generalizables, algunos padres efectivamente presentan un alto compromiso con sus hijos y con la institución educativa, no obstante, es importante subrayar el análisis de los factores contextuales, ambientales y sociales que pueden estar relacionados con el ausentismo de los padres en el proceso educativo de sus hijos, aspectos que pueden ser conducentes a investigaciones futuras, que no fueron objeto de estudio en esta investigación. 


\section{Fortalezas y limitantes en EI: maestros/as e institución educativa}

Una de las fortalezas observada en el cuerpo docente y la institución educativa fue la tranquilidad, satisfacción y agrado de padres/madres y cuidadores por los servicios ofertados por la institución educativa, entre ellos: contar con maestras/os cualificadas/os en el acompañamiento infantil, disponer del servicio psicológico ofrecido a los padres, charlas direccionadas a la crianza de los hijos, alimentación e higiene, didáctica infantil y sobre todo un trato respetuoso y digno hacia sus hijo que se expresa en logros, evidenciados principalmente en el proceso de crecimiento y desarrollo infantil, así como en los procesos afectivos, lúdicos, recreativos, valores, relacionales, cognitivos, entre otros; aspectos que legitiman el nivel de credibilidad y confianza institucional, pero que como se ha analizado anteriormente, no justifican el distanciamiento de los padres en uno de los procesos que, dada su naturaleza y complejidad, requiere una articulación activa y participativa de los padres: "...el proceso lo inició acá, a dejar el pañal, a comer sola. Han sido muchas ventajas en realidad y beneficios de que esté en el Centro Infantil" (Madre 15, 29 años).

En este orden, el nivel de satisfacción de padres, madres y cuidadores está a tono con otros servicios institucionales, que incluyen aspectos nutricionales, lúdicos y recreativos: "Tenerlos bien, estar bien, educarlos... que se alimenten bien" (Madre 15, 29 años). "El centro infantil viene, pues, a intervenir, en cuanto a sus conocimientos, en cuanto a ampliarle más" (Docente 5, 28 años).

Aclaran las maestras que su rol está supeditado al acompañamiento educativo de los niños y niñas, tarea que debe ser complementada por los padres y las madres. Igualmente reiteran que el apoyo educativo no puede ser visto como un reemplazo de los compromisos parentales, aspecto crítico observado en algunos padres y madres, quienes ven a los maestros como sustitutos de los padres; de este modo las maestras generan conciencia en el compromiso institucional en los espacios pensados en la niñez y la familia, entre ellos: la asesoría psicológica, con el nutricionista, las charlas sobre la prevención del maltrato infantil, entre otros, en donde nuevamente generan un llamado a los padres en su vinculación. De igual manera, las expresiones afectivas, cobran representatividad como fortalezas institucionales, así como el acompañamiento didáctico y metodológico propuesto por la institución educativa, lo que es altamente valorada por los padres y las madres, considerado a su vez por el equipo docente como un factor fundamental en EI: "Las fortalezas son muchas, le permiten a mi hijo explorar, que sea un niño seguro y que se sienta amado" (Madre 1, 34 años).

Acorde a estas perspectivas, el acompañamiento en EI, representa un conjunto de acciones articuladas que se gestan inicialmente en el hogar e implican estar al tanto de los hijos, de su afectividad y comportamientos (Villalobos, Flórez y Londoño, 2017); acciones que se continúan y complementan en la institución educativa: "El acompañamiento a los niños, el amor que se les da, que se les brinda, para nosotros es 
muy importante que cada niño siempre que salga de acá, salga feliz, salga contento, salga alegre, salga con nuevas expectativas". (Docente 1, 32 años). Esto permite entablar conexiones estratégicas entre familia e institución educativa, lo que según Pitluk (2016), incluye el conocimiento de lo institucional y su organización teórica, metodológica y práctica, es decir, se precisa de un trabajo colaborativo entre institución y familia para comprender y vivenciar los procesos que facilitan su operatividad, vistas por la autora como "el eje central, y que por lo tanto deben conjugarse para entramar redes con otras familias y otros docentes" (p.30), reiterando, que se debe volver a mirar el lugar que colocan las instituciones a las familias en el contexto de la educación, en donde el proceso de articulación se observa como una política de mejora a la misma.

Por su parte, las prácticas pedagógicas como el juego, constituyen la mejor estrategia para potenciar el aprendizaje en EI, de ahí la necesidad de su fortalecimiento: "Yo creo que mi hijo aprende jugando (...) y esto es mucha ayuda para el aprendizaje" (Madre 13, 36 años). Montero (2017) explica que el juego hace parte del desarrollo humano, de esta forma un componente lúdico ayuda a cumplir y fortalecer el proceso de aprendizaje. Delgado (2016) reitera su alcance al indicar que el juego "contribuye con el desarrollo biopsicosocial del hombre, desarrolla destrezas motrices y el intelecto, ayuda a que conozca el entorno y a la socialización" (p. 174), perspectiva evidenciada en este testimonio: "Le gusta mucho estar con las profesoras, jugar con los compañeros, le gusta ir a jugar a los patios y que la profesora la peine" (Madre 14, 40 años). Al respecto, Andolfi (2003) indica que los profesionales en la intervención infantil deben ayudar a traducir el mundo de los niños, colmado de comunicación no verbal e imágenes concretas.

En cuanto a las limitantes del proceso pedagógico expresadas por el grupo de maestras, éstas refieren preocupaciones vinculadas con las responsabilidades y compromisos de los padres y las madres en el acompañamiento educativo, entre ellas: "llegan tarde a recoger a sus hijos y comentan que se les olvidó que tenían su hijo en la institución" (Docente 4, 30 años). A tono con estas preocupaciones y en virtud de favorecer la funcionalidad y dinamismo de los padres en el acompañamiento educativo de los hijos, Herrera, Bedoya y Alviar (2019) recomiendan un acompañamiento compartido de la familia, en donde se asuma la responsabilidad del cuidado, mediada por una comunicación vinculante y reflexiva, que procure mantener un tiempo prudencial y de calidad en compañía de los hijos. A este grupo de limitantes asociadas al cuidado parental, se vincula el déficit en el cuidado personal de niños y niñas, en donde aspectos como el vestuario, la alimentación, el suministro de medicamentos, entre otros, que afectan el desarrollo integral de niños/as y adolescentes, con efectos colaterales en el proceso educativo: "La presentación personal de los niños es por parte de los papás; porque tú eres el que lo baña, el que lo peina, que lo debe de llevar con ropa limpia, pero en ocasiones eso no es así..." (Docente 3, 26 años).

Ante estas limitantes, Marín y Ospina (2015) plantean que el cuidado de la niñez, representa un componente fundamental en la familia, que implica interacción y 
acompañamiento constante entre quien cuida y quien es cuidado, acciones que se traducen en acompañarlos en la alimentación, llevarlos al jardín o al médico. Sobre este tema manifestaron las maestras entrevistadas que existe un déficit de tiempo y el exceso de actividades de los padres dificultan un acompañamiento educativo real y sentido. A modo crítico, reiteran el escaso interés, motivación y responsabilidad de algunos padres en participar activamente en la formación de sus hijos, son vistas como responsabilidad directa de la institución educativa y con ella, de los maestros (Valdés y Sánchez, 2016). Moreno, et. al (2016), en referencia al tiempo que utilizan los padres para acompañar a sus hijos en las actividades educativas, reitera preocupación por su marcado ausentismo, aclarando que algunos disponen de buena actitud, compromiso, disposición y tiempo de calidad para sus hijos. "De igual forma para los docentes, la familia no se involucra en la escuela debido a que se presentan muchas condiciones de disfuncionalidad que se evidencian en el bajo compromiso de la familia con la escuela y la educación de los niños y niñas" (p. 126).

En sintonía con lo anterior, las limitantes expuestas por padres y cuidadores en EI, obedecen a un escenario multivariado de factores que dificultan la participación activa de los padres en EI, entre ellas: laborales, dificultades familiares, sociales y académicas, entre otros. Valdés y Sánchez (2016) afirman que el déficit de tiempo y las cargas laborales, vinculado a estas el escaso interés y responsabilidad de los padres para participar en las actividades escolares de sus hijos, constituyen factores que limitan un acompañamiento educativo real de los padres. Los padres para tratar de dirimir el nivel de afectación de estos factores, fundamentan una excesiva confianza en el proceso educativo de sus hijos; situación que dimensiona dos elementos de análisis: por un lado, la confianza institucional, puede ser observada como una fortaleza para la entidad, pero por otro, puede leerse como un aspecto negativo, en tanto desde la percepción de los padres de familia, se genera incomprensión de su responsabilidad con el proceso educativo, convirtiéndose en una excusa válida para evadir el acompañamiento educativo de sus hijos como todo lo hacen tan bien, entonces para que voy por allá. El siguiente testimonio ilumina estos niveles de confianza, que como se ha dicho, ameritan reflexividad en padres, madres y cuidadores, para evitar malas interpretaciones frente al rol docente: "Mamá tal cosa, mamá felicitaciones por que Martín es esto, lo otro, entonces siempre hay una comunicación; o si yo tengo que llamar o tal cosa o la profesora, llamo y ya ellos lo atienden a uno súper bien" (Madre 1, 34 años).

Con miras al mejoramiento en este tipo de prácticas parentales, Fuentes, Blandón, Rodríguez y Vásquez (2013, citados por Lastre, López y Alcázar, 2018), refieren que "Los padres de familia realizan un escaso acompañamiento escolar, debido a las prácticas educativas para el aprendizaje limitadas, pocos recursos, falta de tiempo, escolaridad, hábitos de estudio, estrategias, y motivación por parte de los padres" (p.104). De esta manera, los autores visibilizan una realidad familiar, que lejos de cooperar con los procesos educativos, se observa ausente e incluso ajena a las afectaciones que puedan producir en sus hijos. De ahí la posibilidad de aperturas en los procesos de inclusión, en 
donde padres, cuidadores, maestros e institución educativa, faciliten procesos evaluativos, integrativos, de compromiso y responsabilidad para dinamizar y trascender la práctica educativa, que como se indicó anteriormente, no solo es competencia de las instituciones educativas o de lo entes gubernamentales y sociales. En sintonía, el acompañamiento familiar se concibe como un aspecto básico y fundamental en EI, en donde la familia, es vista como un espacio para compartir, acercarse y conocerse: "Nosotros estamos muy pendientes de hablarle, de siempre recordarle las cosas buenas, de dedicarle más tiempo y ser muy cuidadosos con ella" (Madre 1, 34 años).

Frente a estas perspectivas orientadas al bienestar infantil, el MEN (2007) considera que para lograr una educación en condiciones de alta calidad "Es fundamental fortalecer el rol de los padres de familia como formadores y participantes activos del proceso de formación de sus hijos". (p.3). Compartiendo algunas de estas ideas, el Plan Nacional Decenal de Educación 2016 - 2026 (2017), describe algunos objetivos a dimensionar en el sistema educativo, entre ellos: implementar estrategias pedagógico/formativas, con la participación activa de las familias, consideradas los principales agentes educativos y por tanto, responsables del acto educativo, con la articulación de otros actores como el Estado y las instituciones privadas. Un segundo objetivo, articulado con el primero, está referido a reconocer las capacidades y recursos que operan en las familias, al igual que su contexto; acción que se traduce en dotar y fortalecer las habilidades familiares, que en lo sucesivo se pueden traducir en compromisos educativos. Un tercer objetivo responde a hacer efectiva la participación de las familias en el marco de estas acciones institucionales, con el acompañamiento de personal especializado. Asimismo, el acompañamiento educativo desde las familias confirma el hogar como espacio único para el crecimiento, el desarrollo afectivo, cognitivo, relacional, lúdico, creativo y de comunicación de niños y adolescentes: "Nosotros en la casa hablamos mucho, puedo conocer a mi hija, puedo conocer sus cosas buenas y malas". (Madre 14, 40 años). Flórez, Villalobos y Londoño (2017), vinculan al compromiso de ser padres, el acompañamiento, tarea que como se dijo anteriormente, no se agota en la familia, se hace extensivo a educadores e instituciones educativas "Acompañar es una tarea que demanda toda la atención de los tutores: padres/maestros" (p.13).

Acorde con los resultados, padres, madres y maestros/as, observan la necesaria articulación de la diada familia - escuela para favorecer la formación integral de sus hijos: "Yo hasta el momento estoy conforme con todo, con el trato de las profesoras, que le informen a uno siempre cómo van los niños, ellos hacen informes como si estuvieran en un colegio" (Madre 7, 25 años). Gubbins (citado por Ortega y Cárcamo, 2016) en concordancia con este análisis, argumenta que: "La escuela no puede concebirse sin una adecuada relación familia-escuela en la que se exprese la participación activa de padres y madres; los educadores saben que la participación de las familias es fundamental para la comunidad educativa" (p.102), considerando que los vínculos e interacciones entre padres, maestros e instituciones educativas, se conciben fundamentales para garantizar un desarrollo infantil óptimo. De esta forma, la crianza de los hijos está caracterizada por 
el poder, el afecto y la anuencia en la familia, factores decisivos que resignifican el acompañamiento de los padres en el proceso educativo de sus hijos, articulada a esta responsabilidad la función de cuidado y orientación (Herrera, Bedoya y Alviar, 2019).

En esta dirección, siguen teniendo vigencia las afirmaciones de Freire (1970) quien señala que la educación no puede verse como un banco para depositar conocimientos, por el contrario, representa un espacio vital que recrea el desarrollo humano en todas sus dimensiones, fundamental para el proceso de socialización, el servicio social o comunitario, para el encuentro relacional y afectivo; de ahí que la educación en general y especialmente la $E I$ no puede agotarse en un interés instruccional como es el conocimiento, que como bien lo evidencian las maestras, debe partir de un currículo flexible, pensado en la realidad infantil. A propósito, indica una de las maestras que el interés institucional no está propiamente centrado en que los niños y niñas adquieran conocimientos, más bien en facilitar espacios para que los niños y niñas, obtengan bienestar, aspecto que se conjuga con condiciones educativas para el desarrollo del juego, la diversión o simplemente permitirles vivir su niñez: "Velar por el bienestar de los niños, por su alimentación, que ellos disfruten, que se diviertan, permitirles que sean niños" (Docente 4, 30 años).

En virtud de lo expuesto, se requiere que los padres se asuman en el escenario educativo como copartícipes del mismo, al representar y hacer efectiva su responsabilidad, compromiso y seguimiento frente al acompañamiento educativo de los hijos. Tal como señala Unesco (2004): "La educación de las familias, la participación y la articulación entre la familia y la institución o programa educativo, son temas que siempre han estado presentes desde el origen de la educación de la primera infancia" (p.22), aspectos que reiteran una articulación permanente de la diada escuela y familia en contextos de corresponsabilidad: "yo digo que es como la responsabilidad de los dos. Es que es de las dos, tanto del centro educativo como en la casa, primeramente, desde la casa empieza todo" (Docente 2, 27 años).

\section{Conclusiones}

La educación inicial constituye un proceso complejo y exigente que incluye un acompañamiento responsable, cuidadoso y respetuoso por parte de padres, madres, cuidadores/as y maestras/o, aspecto que legitima y vigila la legislación colombiana e internacional. Tanto las instituciones educativas, la sociedad y el Estado, en el marco de la corresponsabilidad, están llamados a consolidar planes, programas y proyectos en primera infancia, traducidos en acciones para asegurar el desarrollo integral de la niñez en condiciones de calidad; mediada por un trabajo colaborativo y articulado. No obstante, la responsabilidad y el compromiso de los padres en EI, se observa limitada por factores laborales, familiares y académicos, entre otros, que impiden un acompañamiento real de este proceso, aspecto que convoca al desarrollo de estrategias institucionales para 
mejorarlo.

En este nivel, la EI precisa de profesionales formados con vocación en el acompañamiento infantil, con atributos y características que les permitan ser intérpretes de su realidad; formación que en ningún momento pretende reemplazar las funciones parentales. Los padres y las madres de familia, por su parte, están convocados al ejercicio de un acompañamiento responsable y comprometido con sus hijos/as, evitando prácticas de delegación parental en especial con maestras/os e instituciones educativas. De este modo, los padres de familia, constituyen la primera escuela de humanización y aprendizaje en donde niños y niñas, aprenden del buen ejemplo, adquieren y vivencian los valores familiares. En este orden, la EI precisa además de padres afectuosos, cálidos y con tiempos de calidad. Las instituciones de EI por su parte, constituyen contextos de apoyo, que complementan y dinamizan este valioso proceso, desde la implementación de recursos humanos, pedagógicos, didácticos y metodológicos flexibles, en concordancia a las necesidades de la niñez, incorporando para ello, el juego, la recreación y la espontaneidad, como insumos vitales que facilitan entender, comprender e interpretar el mundo de niños-as.

Ahora bien, con respecto a los imaginarios educación/Educación Inicial, si bien padres, madres y cuidadores presentan algunas comprensiones sobre EI, se quedan en generalidades, por lo tanto, es necesario que los centros educativos consoliden una plataforma formativa dirigida a padres y cuidadores, encaminada a un mayor conocimiento de este proceso, considerado vital para el desarrollo y crecimiento de la niñez. En este contexto, padres y cuidadores presentan un nivel de acercamiento a ambos conceptos, vistos como guía, acompañamiento, orientación, enseñanza y la adquisición de conocimientos. En relación con este último punto, es importante aclarar que según la perspectiva del equipo docente, la adquisición de conocimientos o aprendizajes no se constituye en un interés principal, se privilegian otro tipo de necesidades en niños y niñas como el juego, la creatividad, los aspectos relacionales, la adquisición de valores personales y familiares, los buenos modales, rutinas, destrezas y las habilidades para la vida, que se adquieren inicialmente en el hogar y se fortalecen en el contexto educativo.

En este sentido, y en coherencia con los resultados del estudio, se identifican estrategias de acompañamiento en EI tendientes al bienestar infantil, entre ellas: la práctica pedagógica, formativa y didáctica, se observa con flexibilidad; pensada y centrada en la realidad infantil. Los padres y las madres, por su parte, generan conciencia de sus limitantes en el acompañamiento en EI, aspecto que no solo confiere su reconocimiento, sino también la voluntad y compromiso por mejorar su marcado ausentismo, que afecta significativamente tareas como compartir un cuento con sus hijos, acompañar una actividad institucional, un juego o una actividad lúdica, entre otras. Situaciones que hacen prudente el diseño e implementación de un sistema evaluativo y de seguimiento, especialmente a los padres, vigilando su nivel de compromiso y participación. Por su parte, las estrategias planteadas por la institución educativa, están articuladas a la normatividad 
nacional planteadas por el Ministerio de Educación, evidenciando ambientes adecuados para el trabajo infantil y con material apropiado acorde con la edad de niños y niñas; la participación padres y cuidadores en las actividades institucionales; uso de las capacidades infantiles para motivar el aprendizaje, como el juego y la lúdica; se incluye igualmente, la implementación de redes tecnológicas de apoyo, para mantener activa la participación de los padres en el proceso educativo de sus hijos, entre otras. Frente a este grupo de estrategias, se desarrolla un componente adicional, que más que una estrategia constituye un eje articulador de este grupo de estrategias institucionales: el amor que deposita el personal docente en el acompañamiento infantil, visto por autores/as e investigadores/as, como un aspecto vital en este tipo de procesos, al cual relacionan propuestas educativas que facilitan el desarrollo cognitivo, relacional, afectivo, lúdico - recreativo, y ambiental, fundamental para el desarrollo presente y futuro de la niñez.

De esta forma y en virtud de los objetivos en EI, el proceso evaluativo, requiere de un mayor diálogo del equipo docente con los padres y madres de familia y cuidadores, resaltando la importancia de su acompañamiento, función que no podrá ser reemplazada por ningún docente. La institución, en este sentido, debe generar claridad en el rol del educador/apara evitar interpretaciones que lleven a los padres a desvirtuar su rol parental, el cual está en correspondencia con el acompañamiento educativo, en este caso, alternado por la institución educativa, el grupo familiar, u otras personas que se configuran como red de apoyo, incluidos vecinos y amigos, sin que estos lleguen a desvirtuar o limitar el ejercicio parental, aspecto que se hizo notorio en algunos cuidadores/as, especialmente abuelas, que a pesar de sentirse a gusto con el acompañamiento en la crianza de sus nietos, no dudan en reconocer que se constituyen en plataforma de apoyo para sus hijos, al no contar con el tiempo para acompañar el proceso de crianza; responsabilidad que según ellos/as es exclusividad de los padres. Queda entonces, en un nivel de incertidumbre, las afectaciones que reciben niños y niñas, merced a las limitantes, especialmente laborales de los padres, que impiden un acompañamiento real en EI. Atribuido en buena parte a una sociedad demandante laboralmente, que limita de manera exponencial el acompañamiento infantil, en donde cada vez es más frecuente ver que ambos padres trabajen, estudien, o vivencien experiencias desde roles simultáneos: amigos, estudiantes, empleados, pareja, padre, madre, entre otros; situaciones que convocan principalmente a los padres, a dimensionar calidad de tiempo, incluyendo un manejo responsable que les evite caer en funciones parentales delegadas, que a lo sumo, ponen en declive sus compromisos y funciones.

Finalmente, es pertinente interrogara la política pública educativa, en pro de agenciar procesos de acompañamiento en EI, en donde padres y madres, cuidadores/as, Estado, sociedad civil e instituciones educativas, estén convocados a generar planes de mejoramiento continuos que contribuyan al bienestar infantil. Por su parte, es importante reiterar los escenarios de corresponsabilidad educativa, dirigidos a un mayor aprestamiento y diligencia para buscar soluciones colaborativas para este propósito, en los que se reitera que los hijos son responsabilidad de los padres; las instituciones educativas, 
constituyen escenarios de socialización y formación secundaria; de ahí que el acompañamiento en crianza y formación para la vida, se inicia en el hogar, tarea que es complementada por los centros educativos, bajo el control y vigilancia del Estado, el cual se concibe garantista del derecho a la educación, en especial la EI.

\section{Referencias}

Álvarez, C. (2016). Crianza-regulación, crianza-emancipación: estado de la cuestión de estudios sobre crianza. Aletheia Revista de Desarrollo Humano, Educativo y Social Contemporáneo, 8(1), 80-99. http://www.scielo.org.co/pdf/aleth/v8n1/v8n1a05.pdf

Andolfi, M. (2003). Terapia familiar. Un enfoque interaccional. México: Paidós.

Banco Mundial. (2018, 12 de noviembre). Educación. https://www.bancomundial.org/es/topic/education/overview\#1

Congreso de la República de Colombia (1994, 8 de febrero). Ley General de Educación. https://www.mineducacion.gov.co/1621/articles-85906_archivo_pdf.pdf

Constitución Política de Colombia. (1991, 13 de junio). http://pdba.georgetown.edu/Constitutions/Colombia/colombia91.pdf

Contreras, E.R. (2013). El concepto de estrategia como fundamento de la planeación estratégica. Pensamiento y gestión, (35), 152-181. https://www.redalyc.org/pdf/646/64629832007.pdf

Delgado, D. (2016). El juego como método para el desarrollo de las habilidades motoras en la preparatoria. Revista científica dominio de las ciencias, 2(4), 164-178. https://dialnet.unirioja.es/servlet/articulo?codigo=5802869

Delors, J. (1996). La educación encierra un tesoro. http://otrasvoceseneducacion.org/archivos/301961

Díaz, H. C. (2018). Investigación cualitativa y análisis de contenido temático. Orientación intelectual de revista Universum. Revista General de Información y Documentación, 28(1), 119-142. https://doi.org/10.5209/RGID.60813

Flórez, G., Villalobos, J y Londoño-Vásquez, D. (2017). El acompañamiento familiar en el proceso de formación escolar para la realidad colombiana: de la responsabilidad a la necesidad. Psicoespacios, 11(18), 1-25. http://revistas.iue.edu.co/index.php/Psicoespacios

Freire, P. (1970). Pedagogía del oprimido. Montevideo: Tierra Nueva. 
Galeano, E. (2004). Diseño de proyectos en la investigación cualitativa. Universidad Eafit.

Gubbins, V. \& Ibarra, S. (2016). Estrategias Educativas Familiares en Enseñanza Básica: Análisis Psicométrico de una Escala de Prácticas Parentales. Psykhe, 25(1), 1-17. http://www.psykhe.cl/index.php/psykhe/article/view/773

Gutiérrez, M. (2018). Estilos de aprendizaje, estrategias para enseñar. Su relación con el desarrollo emocional y "aprender a aprender". Tendencias pedagógicas, (31), http://dx.doi.org/10.15366/tp2018.31.004

Herrera, O., López, M., Osorio, L., Tamayo, M. y Hernández, H. (2017). Educación a lo largo de la vida: aperturas y posibilidades en la educación superior. Revista Virtual Universidad Católica del Norte, 119-142. http://revistavirtual.ucn.edu.co/index.php/RevistaUCN/article/view/947/1394

Herrera, O., Bedoya, L. M. y Alviar, M. M. (2019). Crianza contemporánea: formas de acompañamiento, significados y comprensiones desde las realidades familiares. Revista Virtual Universidad Católica del Norte, (57), 40-59. https://doi.org/10.35575/rvucn.n57a4

Lastre, K., López, L. y Alcázar, C. (2018). Relación entre apoyo familiar y el rendimiento académico en estudiantes colombianos de educación primaria. Psicogente, 21(39), 102115. http://doi.org/10.17081/psico.21.39.2825

Ministerio de Educación de Chile (1990, 10 de marzo). Ley Orgánica Constitucional de Enseñanza. $\quad$ http://www.uchile.cl/portal/presentacion/normativa-yreglamentos/8386/ley-organica-constitucional-de-ensenanza

Maldonado M, B; Benavides E, K y Buenaño C, J. (2017). Análisis dimensional del concepto de estrategia. Revista Ciencia UNEMI, 10(25), 25-35. https://dialnet.unirioja.es/servlet/articulo?codigo $=6645975$

Marín, A., y Ospina, L. (2015). Discursos y prácticas de los padres en torno a la crianza y el cuidado en la primera infancia. Revista Trabajo Social, (17), 61-75. https://es.scribd.com/document/350671723/Discursos-y-practicas-de-los-padres-entorno-a-la-crianza

MEN. (2007) ¿Cómo participar en los procesos educativos de la escuela? (Guía 26), Cartilla para padres de familia. https://www.mineducacion.gov.co/1759/articles120646_archivo_pdf.pdf

MEN. (2014). Serie de orientaciones pedagógicas para la educación inicial en el marco de la atención integral: El sentido de la Educación Inicial. https://www.mineducacion.gov.co/1759/articles- 


\section{0_archivo_pdf_sentido_de_la_educacion.pdf}

MEN. (2016). La educación en Colombia. Revisión de políticas nacionales de educación. /http://dx.doi.org/10.1787/9789264250604-en).

OCDE. https://www.mineducacion.gov.co/1759/articles-356787_recurso_1.pdf

MEN. (2017). Bases curriculares para la educación inicial y preescolar. https://www.mineducacion.gov.co/1759/articles-341880_recurso_1.pdf

MEN. (2020). Lineamientos para inicio de ciclo lectivo y periodo de adaptación en el nivel de educación inicial 2019 - 2020. https://educacion.gob.ec/wpcontent/uploads/downloads/2019/08/Lineamiento-para-inicio-de-ciclo-lectivo-y-periodode-adaptacion-en-Educacion-Inicial-2019-2020.pdf

Montero, B. (2017). Aplicación de juegos didácticos como metodología de enseñanza: Una revisión de la literatura. Revista pensamiento matemático 71$)$ 75-92. https://dialnet.unirioja.es/servlet/articulo?codigo=6000065

Mora, A., y Maestre, A. (2012). Acompañamiento familiar: aportes a la estrategia en el programa «Medellín Solidaria». Revista Trabajo Social, (15), 9-31. https://aprendeenlinea.udea.edu.co/revistas/index.php/revistraso/article/view/24241

Moreno, I., Bermúdez, A., Mora, C.; Torres, D y Ramos, J. (2016) Representaciones sociales de los maestros sobre la familia y su rol en la escuela. Revista Encuentros, 14(01), 19-138. https://www.redalyc.org/pdf/4766/476655851008.pdf

Ortega, M y Cárcamo, H. (2016). Relación familia-escuela en el contexto rural. Miradas desde las familias. Revista Educación, 52(27), 98-118. http://revistas.pucp.edu.pe/index.php/educacion/article/view/19920

Payá, A., y Tormo, M. (2016). Participación educativa de las familias en una escuela pública valenciana. Un estudio cualitativo. Foro de Educación, 14(21), 227-248. https://forodeeducacion.com/ojs/index.php/fde/article/view/394

Pizarro, P., Santana, A., y Vial, B. (2013). La participación de la familia y su vinculación en los procesos de aprendizaje de los niños y niñas en contextos escolares. Diversitas $\begin{array}{llll}\text { perspectivas en psicología, 271-287. } & \text { 9(2), }\end{array}$ https://www.redalyc.org/pdf/679/67932397003.pdf

Pitluk, L. (2016). Articulación entre la educación inicial y la educación primaria: continuidades y encuentros. https://homosapiens.com.ar/\#!/producto/21/

Plan Nacional Decenal de Educación 2016 - 2026. (2017). Compendio General. Pacto Social por la educación. http://www.plandecenal.edu.co/cms/media/herramientas/pnde_2006_2016_compendio 
.pdf

Preciado, S.P. (2014). Fortalecimiento de habilidades para la vida como factores psicosociales en la educación para la resiliencia (Tesis de grado, UNAD). https://repository.unad.edu.co/bitstream/handle/10596/2758/23945691. pdf? sequence=1 \&isAllowed=y

Presidencia de la República (2013). Estrategia de atención integral a la primera infancia. Fundamentos políticos, técnicos y de gestión. http://www.deceroasiempre.gov.co/Prensa/CDocumentacionDocs/Fundamientospoliticos-tecnicos-gestion-de-cero-a-siempre.pdf

Programa Escuelas de Calidad. (2010). Modelo de Gestión Educativa (Módulo 1). Dirección General de Desarrollo de la Gestión e Innovación Educativa de la Subsecretaría de Educación Básica, segunda edición. Secretaría de Educación Pública. http://edu.jalisco.gob.mx/cepse/sites/edu.jalisco.gob.mx.cepse/files/modelo_de_gestio n_educativa_estrategica_modulo_1_pec.pdf

Rivas, S. y Ugarte, C. (2014). Formación docente y cultura participativa del centro educativo: claves para favorecer la participación familia-escuela. Estudios sobre educación,

153-168.

https://www.unav.edu/publicaciones/revistas/index.php/estudios-sobreeducacion/article/view/490

Robinson, K. (2019). Tú, tu hijo y la escuela. Barcelona: Debolsillo.

Rodríguez, R.E. (2018). Imaginarios sociales de primera infancia que construyen las maestras del ciclo inicial en la interacción con los niños y niñas (Tesis de Especialización, Universidad Distrital Francisco José de Caldas). http://repository.udistrital.edu.co/bitstream/11349/8929/1/RodriguezFernandezRodo IfoEsteban2018.pdf

Rodríguez, J. (2019). Lo que dice la ciencia sobre educación y crianza. https://www.plataformaeditorial.com/libro/7846-lo-que-dice-la-ciencia-sobreeducacion-y-crianza

Ruíz, J. (2012). Metodología de la investigación cualitativa. Bilbao, España: Universidad de Deusto.

Sales, A., Moliner, O., Amiama, J., y Lozano, J. (2018). Escuela incluida. Recursos y estrategias para la participación ciudadana. Revista Mexicana de Investigación Educativa, 23(77), 433-458. http://www.scielo.org.mx/scielo. php?pid=S140566662018000200433\&script=sci_arttext 
UNESCO. (1990). Conferencia Mundial sobre Educación para Todos: Satisfacción de las Necesidades Básicas de Aprendizaje. https://www.oei.es/historico/efa2000jomtien.htm

UNESCO. (2000a). Marco de Acción de Dakar de Educación para Todos: cumplir nuestros compromisos

comunes.

https://web.oas.org/childhood/ES/Lists/Recursos\%20\%20Compromisos\%20Mundiales/

Attachments/20/9.\%20Marco\%20de\%20Acci\%C3\%B3n\%20de\%20Dakar\%20Educaci

\%C3\%B3n\%20para\%20Todos.pdf

UNESCO. (2000b). Informe Subregional para América Latina de Evaluación para Todos. OREALC/UNESCO (de cada país: Argentina, Brasil, Bolivia, Colombia, Costa Rica, Chile, Ecuador, El Salvador, Guatemala, Honduras, Nicaragua, México, Panamá, Perú, Paraguay, Venezuela). https://unesdoc.unesco.org/ark:/48223/pf0000152894

UNESCO. (2004). Participación de las familias en la educación infantil latinoamericana. UNESCO.

http://disde.minedu.gob.pe/bitstream/handle/MINEDU/5612/Participaci\%C3\%B3n\%20d e\%20las\%20familias\%20en\%20la\%20educaci\%C3\%B3n\%20infantil\%20latinoamerica na.pdf?sequence $=1$ \&isAllowed $=y$

UNESCO. (2005). Educación para todos: el imperativo de la calidad. https://unesdoc.unesco.org/ark:/48223/pf0000150169

Valdés, A. y Sánchez, P. (2016). Las creencias de los docentes acerca de la participación familiar en la educación. Revista Electrónica de Investigación Educativa, 18(2), 105115. http://redie.uabc.mx/redie/article/view/1174

Villalobos, J., Flórez, G., y Londoño, D. (2017). La escuela y la familia en relación con el alcance del logro académico. La experiencia de la Institución Educativa Antonio José de Sucre de Itagüí (Antioquia) 2015. Revista Aletheia, 9(1), 58-75. http://aletheia.cinde.org.co/index.php/ALETHEIA/article/view/379

\section{Fuente de financiamiento:}

Proyecto financiado por la Universidad Católica Luis Amigó (Medellín) en convenio con la Corporación Por Un Nuevo Santander (Medellín). Fecha de inicio: 02/02/2019, finalización: 28/11/2019. Adscrita al grupo de investigación: Familia, desarrollo y calidad de vida, Línea de investigación: Estudios de Familia (Facultad de Psicología y Ciencias Sociales); en articulación con el Grupo de investigación Infancia y Lenguas Extranjeras, Línea Infancia y Lenguas Extranjeras (Facultad de Educación) de la Universidad Católica Luis Amigó. 